\title{
An Investigation of RNA Synthesis in Anacystis nidulans During Exponential Growth Using Techniques of RNA-DNA Hybridization
}

\author{
By R. JOHN SMITH* AND NOEL G. CARR \\ Department of Biochemistry, University of Liverpool, P.O. Box I47, \\ Liverpool L69 $3 B X$
}

(Received I2 May 1976)

SUMMARY

RNA isolated from exponential-phase cultures of $A$. nidulans was used to titrate denatured DNA over a wide range of RNA: DNA ratios. The following results were obtained: (i) $0.6 \%$ of $A$. nidulans DNA was complementary to purified rRNA and $0.062 \%$ was complementary to tRNA. (ii) Under the growth conditions employed $\left(35^{\circ} \mathrm{C}\right.$; mean generation time $4 \mathrm{~h}$ ), unstable RNA accounted for $40 \%$ of the rapidly labelled RNA fraction but only $2 \%$ of the randomly labelled RNA fraction. The half-life of the unstable RNA was estimated to be $3 \%$ of the mean generation time. (iii) A wide variation in the abundance of unstable RNA species was observed; more than $80 \%$ of the labelled RNA in both rapidly and randomly labelled unstable RNA fractions was homologous to only $10 \%$ of the DNA that was actively transcribed (i.e. I \% of the total DNA). In turn, the actively transcribed DNA comprised only $10 \%$ of the total DNA since virtually all the unstable and readily hybridizable RNA fraction ( $>99 \%$ ) from rapidly and randomly labelled RNA would form stable hybrid with it. This indicated that the remaining fraction of the DNA $(90 \%)$ was infrequently transcribed.

\section{INTRODUCTION}

Knowledge of macromolecule composition and synthesis in blue-green algae has arisen mainly from comparative studies with a limited number of species which emphasized the structural and functional similarities with the other prokaryotes (see Leach \& Herdman, 1973). RNA content per cell of Anacystis nidulans increased with increased growth rate, such that at $35^{\circ} \mathrm{C}$ each cell contained $5 \times 10^{-1}$ fg RNA when grown at a mean generation time of $10 \mathrm{~h}$ and $23 \times 10^{-1} \mathrm{fg}$ RNA at a mean generation time of $3.3 \mathrm{~h}$ (Mann \& Carr, 1974). RNA synthesis appeared to be modulated by growth rate in a manner comparable to that in heterotrophic bacteria (see Maaløe \& Kjeldgaard, I966) although the ratio of rRNA to tRNA remained constant over a range of division times (Mann \& Carr, I973). Anacystis nidulans also differed from heterotrophic bacteria in that the rate of increase of RNA content per cell, with increasing growth rate, paralleled the rate of increase of DNA content rather than exceeding it.

The control of RNA synthesis in blue-green algae is of particular interest since it has been demonstrated in several species, notably $A$. nidulans and Anabaena variabilis, that many of the enzymes are constitutive (see Carr, 1973). The synthesis of several groups of enzymes has been shown to be neither repressed nor derepressed by the presence or absence of their endproducts. For example, in contrast to several bacterial species, the formation of the first enzyme in the synthesis of methionine, homo- $O$-transsuccinylase, was not repressed by

* Present address: Department of Biological Sciences, University of Lancaster, Lancaster LAI 4 YQ. 
methionine (Delaney, Dickson \& Carr, 1973) in either wild-type or a methionine auxotroph of $A$. nidulans. There are some examples of apparent transcriptional control in this organism (Abeliovich, Kellenberg \& Shilo, 1974; Ihlenfeldt \& Gibson, 1975; Singer \& Doolittle, 1975) although the caution expressed by Wan, Floyd \& Hatch (1975) in attributing alteration in enzyme activity to control of enzyme synthesis rather than to persistent feedback inhibition in the unicellular blue-green alga Synechococcus cedrorum should be noted. Reduction in the rate of RNA synthesis following a shift-down in growth rate is accompanied by an increase in the concentration of guanosine $5^{\prime}$-diphosphate- $3^{\prime}$-diphosphate (ppGpp), indicating a stringent response in the linking of RNA synthesis to cell growth (Mann, Carr \& Midgley, 1975). It has been suggested that in Escherichia coli ppGpp is concerned in the control of stable RNA synthesis (Cashel, I969; Travers, Kamen \& Cashel, I970).

This paper examines RNA synthesis in steadily growing cultures of $A$. nidulans and includes estimations of the content and relative rates of synthesis of the unstable and stable RNA fractions. The data is interpreted in terms of the transcriptional activity on the various complementary fractions of the genome.

\section{METHODS}

Culture conditions. Anacystis nidulans (Culture Collection of Algae, Indiana University, strain 625) was grown in medium C (Kratz \& Myers, I955) modified by the addition of Tris $\left(0.4 \mathrm{~g} \mathrm{l}^{-1}\right)$ and reduction of the $\mathrm{KH}_{2} \mathrm{PO}_{4}$ concentration to $7 \cdot 0 \times 10^{-5} \mathrm{M}$. The medium was adjusted to $\mathrm{pH} 7.8$ with $\mathrm{I} \mathrm{M}-\mathrm{HCl}$ before autoclaving. Experimental cultures (I l) were maintained at $35 \pm 0 . \mathrm{I}{ }^{\circ} \mathrm{C}$ and gassed with air $/ \mathrm{CO}_{2}(95: 5, \mathrm{v} / \mathrm{v})$ at $50 \mathrm{ml} \mathrm{min}{ }^{-1}$. Illumination was provided by two $75 \mathrm{~W}$ reflector lamps (Cryselco, Kempton Works, Bedford) placed I $2 \mathrm{~cm}$ from either side of the culture vessel; the incident light intensity was I 994 klux. These conditions resulted in a mean generation time of 230 to $240 \mathrm{~min}$. Growth was measured at $650 \mathrm{~nm}$ using a Gilford spectrophotometer.

Preparation of nucleic acids. Nucleic acids were isolated as described by Pigott \& Midgley (I968). ${ }^{32} \mathrm{P}-\mathrm{labelled}$ DNA was prepared by allowing a continuous uptake of [ $\left.{ }^{32} \mathrm{P}\right]$ orthophosphate (specific radioactivity $100 \mathrm{Ci} \mathrm{g}^{-1}$, final concentration $\mathrm{I} \mu \mathrm{Ci} \mathrm{ml}^{-1}$ ) for six generations of exponential growth. Cells were harvested by centrifuging (100000 $\mathrm{g}$ for $\mathrm{I} 5 \mathrm{~min}$ at $4{ }^{\circ} \mathrm{C}$ ), mixed with a larger quantity of unlabelled wet packed cells and suspended (I00 to $200 \mathrm{mg}$ wet wt $\mathrm{ml}^{-1}$ ) in $0 . \mathrm{I} \mathrm{M-EDTA/0.4} \mathrm{M}-\mathrm{NaCl}, \mathrm{pH} \mathrm{8.0.} \mathrm{The} \mathrm{suspension} \mathrm{was} \mathrm{treated} \mathrm{with} \mathrm{lysozyme}$ ( $500 \mu \mathrm{g} \mathrm{ml}^{-1}$; Sigma, grade I) for $30 \mathrm{~min}$ at $37^{\circ} \mathrm{C}$ (Craig, Leach \& Carr, I969) before proceeding with cell lysis as described by Pigott \& Midgley (1968). DNA yield was poor [0.48 mg ( $\mathrm{g}$ wet wt of packed cells) ${ }^{-1}$, due possibly to incomplete cell lysis.

Total RNA was prepared from exponential-phase cultures with an extinction $E_{650}$ of $0.5 \pm 0.05$. Total RNA, containing radioactivity in the stable RNA fractions only, was prepared from late exponential-phase cultures. These cultures were supplemented with a 2000-fold excess of unlabelled orthophosphate and incubated for a further cell generation time before harvesting in order to chase radioactivity from the unstable RNA fraction. Rapidly labelled RNA was prepared by allowing rapidly growing cultures $\left(E_{650} 0.4\right)$ to incorporate [ ${ }^{32} \mathrm{P}$ ]orthophosphate (specific radioactivity $300 \mathrm{Ci}^{-1}$, final concentration $3 \mu \mathrm{Ci} \mathrm{m}^{-1}$ ) for $4 \mathrm{~min}$. The cells were then poured into crushed ice and harvested at $4{ }^{\circ} \mathrm{C}$.

The supernatant obtained from the ribosome sedimentation step (Pigott \& Midgley, I968) was used to prepare tRNA. After DNAase treatment and deproteinization, the RNA was purified by repeated fractionation on polylysine keiselguhr columns using a linear gradient between 0.4 and $4.5 \mathrm{M}-\mathrm{NaCl}$ in phosphate buffer $\mathrm{pH} 7 \cdot 2$. The pancreatic ribonuclease- 
sensitive material eluting as a sharply defined peak at $\mathrm{I} M-\mathrm{NaCl}$ was taken as the purified tRNA.

RNA-DNA hybridization. The nitrocellulose filter technique of Gillespie \& Spiegelman (1965) was used as described by Pigott \& Midgley (1968). All filters were presoaked in Io $\times$ SSC buffer (0.1 $5 \mathrm{M}-\mathrm{NaCl} / 0.0 \mathrm{I} 5 \mathrm{M}$-trisodium citrate, $\mathrm{pH} 7.3)$ for 5 days before use. This procedure reduced non-specific binding of RNA during hybridization. Filters were loaded with $0 \cdot 1$ to I00 $\mu \mathrm{g}$ denatured DNA. Measurements on filters taken through the hybridization procedure showed that in no case was more than $1 \%$ of the initial DNA load lost; the average loss was $0.3 \%$. After the hybridization incubation $\left(\mathrm{I} 6 \mathrm{~h}\right.$ at $\left.66{ }^{\circ} \mathrm{C}\right)$ the filters were washed on either side with $50 \mathrm{ml} 6 \times \mathrm{SSC}$ buffer and then incubated for $\mathrm{I} \mathrm{h}$ at $37^{\circ} \mathrm{C}$ in $2 \mathrm{ml} \mathrm{I} \times \mathrm{SSC}$ buffer containing Io $\mu \mathrm{g}$ pancreatic ribonuclease (EC 3.1.4.22; BDH). The results were corrected for the efficiency of the hybridization reaction and for non-specific adsorption of any RNA which had resisted pancreatic ribonuclease digestion, using filters containing no DNA (Pigott \& Midgley, I968).

\section{RESULTS}

\section{Titration of denatured DNA with stable RNA}

The fraction of the stable RNA capable of forming pancreatic ribonuclease-resistant hybrids with DNA was determined for a series of increasing RNA:DNA input ratios. The fraction of the denatured DNA input hybridized to rRNA (Fig. I $a$ ) or tRNA (Fig. I $b$ ) as a function of the RNA: DNA input was measured. The titration curves for both rRNA and tRNA are comparable with those normally found for bacterial stable RNA (Kennell, I968; Pigott \& Midgley, 1968). The DNA sites capable of forming true hybrids with rRNA became saturated at a RNA:DNA input ratio of $\mathrm{I}: 80$; those sites capable of accepting tRNA became saturated at a ratio of $\mathrm{I}: \mathrm{I} 4$. When complementary sites were fully saturated, $0.64 \%$ of the DNA was hybridized to rRNA and $0.062 \%$ to tRNA indicating that $0.7 \%$ of the $A$. nidulans genome codes for stable RNA.

\section{Titration of denatured DNA with total RNA}

The fraction of randomly labelled total RNA capable of forming pancreatic ribonucleaseresistant hybrids is shown as a function of the RNA:DNA input in Fig. 2. Although nonspecific adsorption of RNA increased more rapidly than true hybrid formation as the RNA input was increased, reproducible results that agreed within $10 \%$ were obtained even at high RNA:DNA ratios. Non-specific adsorption was kept within acceptable limits by the use of presoaking techniques combined with thorough washing of the filters both before and after the pancreatic ribonuclease incubation.

To distinguish messenger and stable RNA fractions, $A$. nidulans DNA was titrated with total randomly labelled RNA and, in another experiment using the same hybridization procedure, with an RNA extract differing only in that the radioactivity in the unstable RNA fraction had been removed by chasing with a 2000-fold excess of unlabelled orthophosphate for at least $4 \mathrm{~h}$. The difference between the two curves (Fig. 2) provides an estimate of the contribution made by the unstable RNA fraction to the titration of the DNA at that RNA: DNA input ratio.

The titration curves show that the stable RNA species saturate their complementary DNA sites at considerably lower RNA:DNA input ratios than do the unstable RNA species. Not only do the unstable RNA species form a smaller proportion of the input RNA, but they are also complementary to a larger fraction of the DNA than are the stable RNA species. Thus a significant contribution to the hybrid from the unstable RNA species is not apparent 

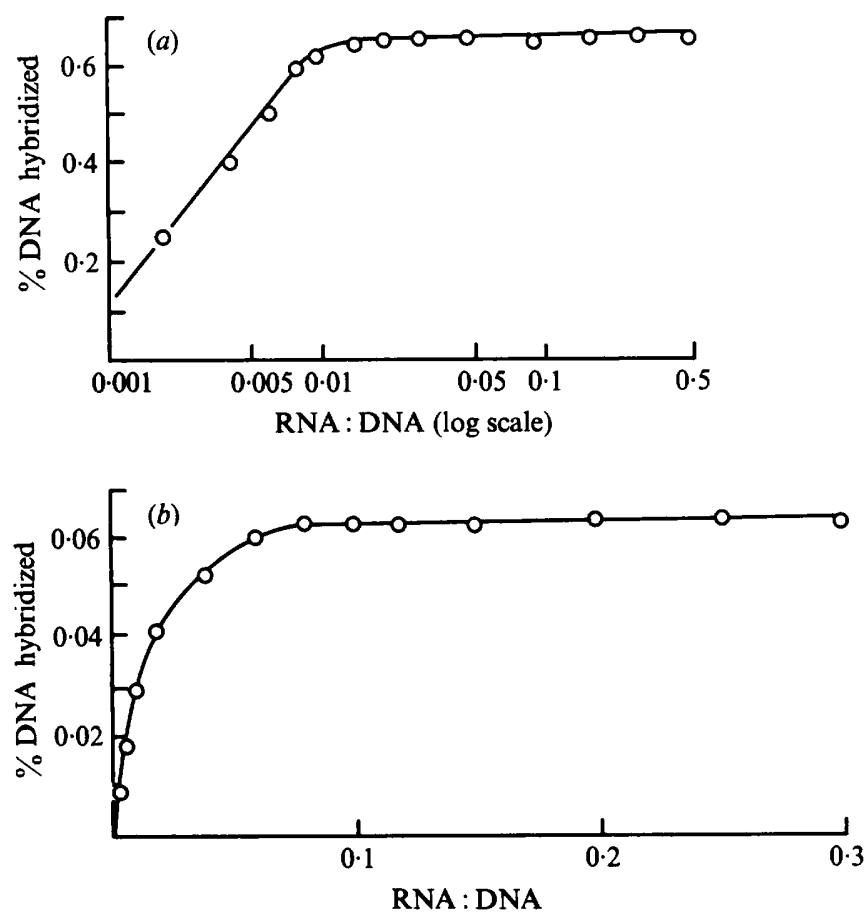

Fig. I. Titration of denatured DNA with stable RNA fractions: (a) ribosomal RNA; $(b)$ transfer RNA. The percentage of filter-bound DNA that formed hybrids is plotted against the RNA:DNA input ratio. Results were corrected as described in Methods.

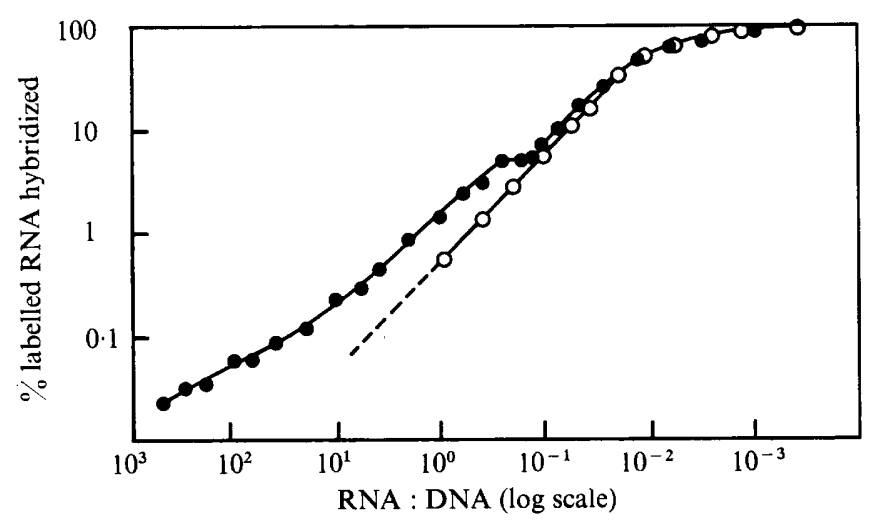

Fig. 2. Titration of denatured DNA with randomly labelled total cell RNA. Percentage of labelled RNA input forming hybrid plotted against RNA:DNA input. $\bigcirc$, Percentage of labelled RNA input forming hybrid, when the total cell RNA contains radioactivity in stable RNA only, plotted against RNA:DNA input (corrected to a maximum of $98 \%$, see text). The difference between these curves gives an estimate of the fraction of input RNA that is unstable RNA. Results were corrected as described in Methods. 


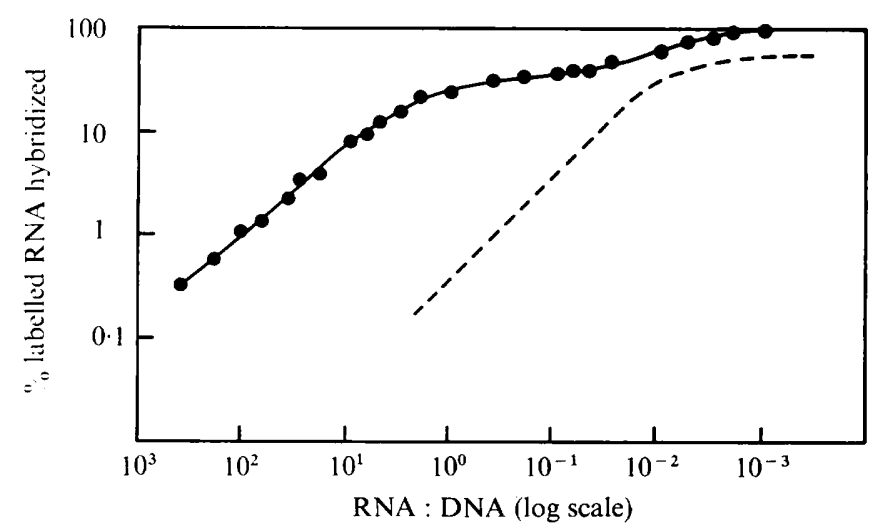

Fig. 3. Titration of denatured DNA with rapidly labelled total cell RNA. Percentage of labelled RNA input forming hybrid plotted against RNA:DNA input. Dashed line shows the titration of stable RNA, reproduced from Fig. 2, corrected to a maximum contribution of $60 \%$ (see text). Results were corrected as described in Methods.

until the RNA:DNA input ratio is $0 \cdot 2$. The unstable RNA fraction may therefore also be described as that RNA fraction which hybridizes efficiently with DNA at high RNA:DNA ratios. Such 'readily hybridizable' RNA fractions are commonly equated with messenger RNA (Kennell, I968). In this instance an additional criterion, that of mRNA instability, has been observed. The slight plateau beginning at the input ratio of 0.2 signifies that most of the unstable RNA fraction is complementary to a relatively small fraction of the DNA. However, as total saturation is not achieved even at high RNA:DNA ratios, infrequent unstable RNA species must still be contributing to hybrid formation.

The proportion of unstable RNA in the total RNA input may be measured at an RNA: DNA input of $0 \cdot 2$. At this ratio the most abundant unstable RNA species begin to saturate their complementary DNA sites. Some $4.8 \%$ of the RNA input forms stable hybrids under the conditions employed, of which $2.9 \%$ is contributed by the stable RNA fraction. Thus nearly $2.0 \%$ of the total RNA is unstable, and the stable RNA species comprise $98 \%$ of the total RNA in a rapidly growing culture of $A$. nidulans. For this reason the hybridization curve for total cell RNA containing radioactivity only in stable RNA fractions was corrected to a maximum value of $98 \%$ in accounting for the efficiency of the hybridization technique (Kennell, 1968).

In a similar manner to that described for randomly labelled RNA, the fraction of the radioactivity in rapidly labelled RNA that formed hybrids was determined as a function of the RNA:DNA input ratio (Fig. 3). Again the titration curve reaches a plateau at an RNA:DNA input ratio of 0.2 though it is more pronounced than that seen in Fig. 2 . Estimates made at this input ratio indicate that about $40 \%$ of the ${ }^{32} \mathrm{P}$ present in hybrids is contributed by the unstable RNA fraction. The dashed line in Fig. 3 represents the hybridization of total cell RNA containing ${ }^{32} \mathrm{P}$ in stable RNA only. The curve is reproduced from Fig. 2 but the maximum contribution was set at $60 \%$, the estimated proportion of stable RNA in the rapidly labelled fraction.

\section{Frequency of transcription of $m R N A$ coding sites}

The data contained in the DNA titration curves for rapidly and randomly labelled RNA Figs 2 and 3) may be expressed in terms of the relative activity of the sites within the genome which give rise to the unstable RNA fraction. Figures $4(a)$ and $(b)$ were generated using 


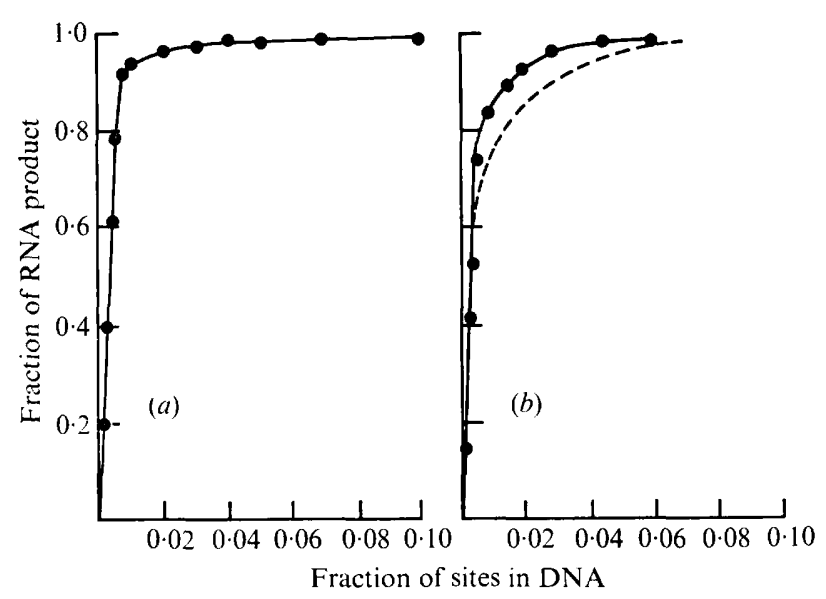

Fig. 4. The fraction of mRNA complementary to a fraction of the DNA input for $(a)$ randomly labelled RNA, (b) rapidly labelled RNA. The values were derived from Fig. 2 and Fig. 3 respectively according to the method of Kennell (1968). The dashed line in Fig. $4($ b) was constructed assuming that corrections to account for the effect of nucleic acid concentrations on the efficiency of the hybridization reaction were required to the full extent described by Kennell (1968) and Kennell \& Kotoulas (1968).

a simple arithmetical procedure devised by McCarthy \& Bolton (I964) as modified by Kennell (I968) and essentially depict saturation curves for the titration of DNA with the unstable RNA fractions of rapidly or randomly labelled RNA. The results indicate that nearly all the unstable RNA detected by the hybridization assay (greater than $99 \%$ ) was complementary to only I0 \% of the genome (Fig. 4). Furthermore, the larger fraction of this RNA (80 to $90 \%$ ) is complementary to less than $\mathrm{I} \%$ of the DNA or $10 \%$ of the actively transcribed genes.

No fraction of the unstable RNA appeared to be effectively more stable than the rest. When DNA was titrated against total RNA containing ${ }^{32} \mathrm{P}$ in the stable RNA fraction only, a uniform saturation plateau was observed even at high RNA:DNA ratios (Fig. 2). If a significant fraction of the mRNA species were relatively stable, they would be expected to contribute to the hybrid formed. There is also little difference between the frequency distribution for rapidly labelled and long labelled unstable RNA (Fig. 4). This does not exclude the possibility that infrequent transcripts may be relatively stable but are present at concentrations too low to be detected by the hybridization assay (Pigott \& Midgley, I968; Kennell, 1968).

When one strand of DNA is transcribed and $10 \%$ of the DNA is complementary to virtually all the RNA detected, only $20 \%$ of the potential gene material is expressed. It is unlikely that the quiescent gene material is incompetent in forming hybrid with complementary RNA (Nygaard \& Hall, 1964; Kennell, 1968). Therefore it appears that $80 \%$ of the potential gene material is very rarely expressed in steadily growing $A$. nidulans cultures.

When DNA is filter-bound the efficiency of hybridization is a function of the nucleic acid concentration. This dependence is most pronounced when infrequent RNA species form a large fraction of the total RNA input, as in rapidly labelled RNA, and when the RNA:DNA input ratio is high, I: Io (Kennell \& Kotoulas, I968). Using filters bearing various amounts of DNA, the effect of RNA concentration was assessed by comparing samples of the same RNA:DNA input ratio. For each RNA:DNA input the maximum attainable percentage 
of ${ }^{32} \mathrm{P}$ incorporation into hybrid was measured. Although this procedure may lead to an underestimate of the maximum efficiency of hybrid formation at high RNA:DNA input ratios, the interpretation of the titration in terms of the relative activity of the mRNA sites within the genome is not unduly affected (see Fig. $4 b$ ).

\section{DISCUSSION}

The variation in abundance of individual RNA species in E. coli has been noted by McCarthy \& Bolton (1964) and Kennell (1968). Our results shows that such variation is apparent in $A$. nidulans and, in common with $E$. coli, probably arises from differences in the frequency of transcriptional events on the various gene sites rather than from variation in the stability of individual transcripts. As the fraction of the genome complementary to stable RNA is relatively small the proportion of rapidly labelled RNA that is stable RNA would suggest that the stable RNA cistrons are among the most frequently transcribed fractions of the genome. Crowding of RNA polymerase molecules on E. coli rRNA cistrons (Mueller \& Bremer, 1968) influences the expression of rRNA and mRNA cistrons during purine deprivation (Varney, Thomas \& Burton, 1970; Smith \& Midgley, 1973).

Variation in abundance of RNA species was, however, most apparent in the unstable RNA fraction of $A$. nidulans; virtually all of this fraction detected was complementary to only $10 \%$ of the DNA. Thus only $20 \%$ of the potential gene material of $A$. nidulans is actively transcribed. Furthermore $90 \%$ of the unstable RNA was complementary to only $10 \%$ of this actively transcribed DNA fraction (i.e. $2 \%$ of the potential gene material). Since the variation in abundance is continuous, each transcript having a characteristic rate of synthesis, one may attribute the variation to differential rates of initiation of new RNA chains. The initiation mechanism may be governed by the affinity of RNA polymerase for the promoter site (Scaife \& Beckwith, I966) of individual cistrons. Thus even when no other form of regulation is present the maximum rate of expression of a cistron would be governed by an aspect of the promoter site involved in the RNA polymerase initiation mechanism (cf. Travers, 1974). An additional or alternative explanation may be the reiteration, to varying degrees, of genes which lead to differential rates of mRNA synthesis. The wide range of mutation rates leading to auxotrophic strains of $A$. nidulans could also be interpreted as being a consequence of multiple gene sites coding for enzyme proteins. It is noteworthy that we report here a more extensive gene duplication for stable RNA cistrons in $A$. nidulans than is reported to exist in E. coli (Avery, Midgley \& Pigott, I969).

If the unstable and readily hybridized RNA fraction is equated with mRNA the results allow a description of the mRNA pool present in rapidly growing $A$. nidulans. The relative flux of labelled precursors into unstable RNA would suggest that $40 \%$ of the RNA synthesized is mRNA. Being unstable, however, this fraction is not accumulated and thus represents only $2 \%$ of the total cellular RNA. From these data, the average half-life of the unstable RNA species in the pool is estimated, assuming an exponential mode of decay, as approximately $7 \mathrm{~min}$ or $3 \%$ of the mean generation time of the culture. Comparable results were obtained for Anabaena variabilis by Leach \& Carr (1974) who estimated the average half-life of the unstable RNA fraction to be 10 min or $3 \%$ of the generation time.

Finally two aspects of the present study require elaboration. Anacystis nidulans has been shown to contain a 'small' labile mRNA pool. This characteristic is a necessary prerequisite of the 'stop/go' mechanisms of induction and repression (Jacob \& Monod, I96I) as distinct from the regulation of transcriptional frequency suggested above. In view of the apparent lack of such regulation in A. nidulans (Carr, 1973), this rapid turnover may 
indicate the requirement to effectively extend the size of the ribonucleoside phosphate pool as an insurance against lack of precursor in unfavourable growth conditions.

A large fraction of the genome of $A$. nidulans, some $80 \%$ of the potential gene material, manufactures no detectable RNA product in the growth conditions employed. Although the non-transcribed DNA may be ascribed roles relating to gene punctuation and regulation, or potential gene evolution, these appear insufficient to account for the size of the quiescent fraction.

These studies were supported by the Science Research Council.

\section{REFERENCES}

Abeliovich, A., Kellenberg, D. \& Shilo, M. (1974). Effect of photooxidative conditions on levels of superoxide dismutase in Anacystis nidulans. Photochemistry and Photobiology 19, 379-382.

Avery, R. J., Midgley, J. E. M. \& PigotT, G. H. (I969). An analysis of the ribosomal ribonucleic acids of Escherichia coli by hybridization techniques. Biochemical Journal I15, 395-403.

CARR, N. G. (1973). Metabolic control and autotrophic physiology. In The Biology of Blue-Green Algae, pp. 39-65. Edited by N. G. Carr and B. A. Whitton. Oxford: Blackwells Scientific Publications.

CASHEL, M. (1969). The control of ribonucleic acid synthesis in Escherichia coli. IV. Relevance of unusual phosphorylated compounds from amino acid starved stringent strains. Journal of Biological Chemistry 244, 3133-3141.

Craig, I. W., LeACH, C. K. \& CARR, N. G. (1969). Studies with deoxyribonucleic acid from blue-green algae. Archiv für Mikrobiologie 65, 21 8-227.

Delaney, S. F., Dickson, A. \& CARR, N. G. (I973). The control of homoserine- $O$-transsuccinylase in a methionine-requiring mutant of the blue-green alga Anacystis nidulans. Journal of General Microbiology 79, 89-94.

GiLlESPIE, D. \& SPIEGELMAN, S. (I965). A quantitative assay for DNA-RNA hybrids with DNA immobilized on a membrane. Journal of Molecular Biology 12, 829-842.

IhlenfFLDT, M. J. A. \& Gibson, J. (1975). Phosphate utilisation and alkaline phosphatase activity in Anacystis nidulans (Synechococcus). Archives of Microbiology 102, 23-28.

JACOB, F. \& MONOD, J. (196r). Genetic regulatory mechanism in the synthesis of proteins. Journal of Molecular Biology 3, 318-356.

KeNNELL, D. (1968). Titration of gene sites on DNA by DNA-RNA hybridization. Il. The Escherichia coli chromosome. Journal of Molecular Biology 34, 85-103.

Kennell, D. \& Kotoulas, K. (I968). Titration of the gene sites on DNA by DNA-RNA hybridization. I. Problems of measurement. Journal of Molecular Biology 34, 7I-84.

Kratz, W. A. \& MYers, J. (1955). Nutrition and growth of several blue-green algae. American Journal of Botany 42, 282-287.

LEACH, C. K. \& CARR, N. G. (I974). In vitro protein synthesis and measurements of the stability of messenger RNA in the blue-green algae, Anabaena variabilis. Journal of General Microbiology 81, 47-58.

LEACH, C. K. \& HeRDMAN, M. (1973). Structure and function of nucleic acids. In The Biology of Blue-Green Algae, pp. 186-200. Edited by N. G. Carr and B. A. Whitton. Oxford: Blackwells Scientific Publicationsn

MaAløe, O. \& KJeldgaARD, N. O. (1966). Control of Macromolecular Synthesis. New York: W. A.. Benjamin.

MANN, N. \& CARR, N. G. (1973). A constant ratio of transfer to ribosomal ribonucleic acid in Anacystis nidulans grown with differing mean generation times. Biochemical Society Transactions 1, 702-704.

MANN, N. \& CARR, N. G. (1974). Control of macromolecular composition and cell division in the bluegreen alga Anacystis nidulans. Journal of General Microbiology 83, 399-405.

MANN, N., CARR, N. G. \& Midglex, J. E. M. (I975). RNA synthesis and the accumulation of guanine nucleotides during growth shift-down in the blue-green alga Anacystis nidulans. Biochimica et biophysica acta 402, 4I-50.

McCARTHY, B. J. \& BolTON, E. T. (1964). Interaction of complementary RNA and DNA. Journal of Molecular Biology 8, I84-200.

Mueller, K. \& BREMER, H. (1968). Rate of synthesis of messenger ribonucleic acid in Escherichia coli. Journal of Molecular Biology 38, 329-353.

NyGAARD, A. P. \& HALL, B. D. (I964). Formation and properties of RNA-DNA complexes. Journal of Molecular Biology 9, 125-142.

PigotT, G. H. \& MidGLEY, J. E. M. (1968). Characterization of rapidly labelled ribonucleic acid in Escherichia coli by deoxyribonucleic acid-ribonucleic acid hybridization. Biochemical Journal 110, 25I-263. 
SCAIFE, J. \& BeCKwith, J. R. (I966). Mutational alteration of the maximal level of lac operon expression. Cold Spring Harbor Symposia on Quantitative Biology 3r, 403-408.

Singer, R. A. \& DoolitTLE, W. F. (I975). Control of gene expression in blue-green algae. Nature, London $253,650-651$.

Smith, R. J. \& Midgley, J. E. M. (I973). The effect of trimethoprim on macromolecular synthesis in Escherichia coli. General effect on ribonucleic acid and protein synthesis. Biochemical Journal $\mathbf{r}_{\mathbf{3}} \mathbf{6}$, 225-234.

TraVers, A. (1974). RNA polymerase-promoter interactions: some general principles. Cell 3, 97-I04.

Travers, A., Kamen, R. \& Cashel, M. (1970). The in vitro synthesis of ribosomal RNA. Cold Spring Harbor Symposia on Quantitative Biology 35, 415-417.

Varney, N. F., Thomas, G. A. \& Burton, K. (1970). Synthesis of ribonucleic acid in purine deficient Escherichia coli and comparison with the effects of amino acid starvation. Biochemical Journal r2o, I 28-132.

WAN, A. Y. L., Floyd, K. W. \& HATCH, M. T. (1975). Inhibition of glutamate transport in Synechococcus cedrorum by glutamine. Journal of Bacteriology 124, 1039-1040. 